\title{
Higher Hemoglobin A1c After Discharge Is an Independent Predictor of Adverse Outcomes in Patients With Acute Coronary Syndrome

\author{
- Findings From the PACIFIC Registry -
}

Keiji Noguchi, MD; Mamoru Sakakibara, MD; Naoya Asakawa, MD; Yusuke Tokuda, MD; Kiwamu Kamiya, MD; Takashi Yoshitani, MD; Koji Oba, PhD; Katsumi Miyauchi, MD; Yuji Nishizaki, MD; Hisao Ogawa, MD; Hiroyoshi Yokoi, MD; Masayasu Matsumoto, MD; Masafumi Kitakaze, MD; Takeshi Kimura, MD; Tetsuo Matsubara, MD; Yuji Ikari, MD; Kazuo Kimura, MD; Hideki Origasa, PhD; Takaaki Isshiki, MD; Yoshihiro Morino, MD; Hiroyuki Daida, MD; Hiroyuki Tsutsui, MD on behalf of the PACIFIC investigators

\begin{abstract}
Background: Optimal medical therapy (OMT) and the management of coronary risk factors are necessary for secondary prevention of major adverse cardiac and cerebrovascular events (MACCE) in post-acute coronary syndrome (ACS) patients. However, the effect of post-discharge patient adherence has not been investigated in Japanese patients.

Methods and Results: The Prevention of AtherothrombotiC Incidents Following Ischemic Coronary Attack (PACIFIC) registry was a multicenter, prospective observational study of 3,597 patients with ACS. Death or MACCE occurred in 229 patients between hospitalization and up to 1 year after discharge. Among 2,587 patients, the association between OMT adherence and risk factor control at 1 year and MACCE occurring between 1 and 2 years after discharge was assessed. OMT was defined as the use of antiplatelet agents, angiotensin-converting enzyme inhibitors, $\beta$-blockers, and statins. Risk factor targets were: low-density lipoprotein-cholesterol $<100 \mathrm{mg} / \mathrm{dl}, \mathrm{HbA} 1 \mathrm{c}$ $<7.0 \%$, non-smoking status, blood pressure $<130 / 80 \mathrm{mmHg}$, and $18.5 \leq$ body mass index $\leq 24.9 \mathrm{~kg} / \mathrm{m}^{2}$. The incidence of MACCE was $1.8 \%$ and associated with female sex $(P=0.020)$, age $\geq 75$ years $(P=0.004), \mathrm{HbA1c} \geq 7.0 \%(P=0.004)$, LV ejection fraction $<35 \%(P<0.001)$, estimated glomerular filtration rate $<60 \mathrm{ml} / \mathrm{min}(P=0.008)$, and history of cerebral infarction $(P=0.003)$. In multivariate analysis, lower post-discharge $\mathrm{HbA} 1 \mathrm{c}$ was strongly associated with a lower risk of MACCE after ACS $(\mathrm{P}=0.004)$.
\end{abstract}

Conclusions: Hyperglycemia after discharge is a crucial target for the prevention of MACCE in post-ACS patients. (Circ J 2016; 80: 1607-1614)

Key Words: Acute coronary syndrome; HbA1c; Major adverse cardiac and cerebrovascular events; Secondary prevention

Received November 10, 2015; revised manuscript received April 14, 2016; accepted April 18, 2016; released online May 19, 2016 Time for primary review: 23 days

Department of Cardiovascular Medicine, Hokkaido University Graduate School of Medicine, Sapporo (K.N., M.S., N.A., Y.T., K. Kamiya, T.Y., H.T.); Department of Biostatistics, School of Public Health, Graduate School of Medicine, The University of Tokyo, Tokyo (K.O.); Department of Cardiovascular Medicine, Juntendo University School of Medicine, Tokyo (K.M., Y.N., H.D.); Department of Cardiovascular Medicine, Graduate School of Medical Sciences, Kumamoto University, Kumamoto (H. Ogawa); National Cerebral and Cardiovascular Center, Suita (H. Ogawa); Department of Cardiology, Fukuoka Sanno Hospital, Fukuoka (H.Y.); Department of Clinical Neuroscience and Therapeutics Division of Integrated Medical Science, Graduate School of Biomedical Sciences, Hiroshima University, Hiroshima (M.M.); Cardiovascular Division, National Cerebral and Cardiovascular Center, Suita (M.K.); Department of Cardiovascular Medicine, Graduate School of Medicine, Kyoto University, Kyoto (T.K.); Toyohashi Heart Center, Toyohashi (T.M.); Department of Cardiology, Tokai University School of Medicine, Isehara (Y.I.); Division of Cardiology, Yokohama City University Medical Center, Yokohama (K. Kimura); Division of Biostatistics and Clinical Epidemiology, School of Medicine and Pharmaceutical Sciences, University of Toyama, Toyama (H. Origasa); Division of Cardiology, Department of Internal Medicine, Teikyo University School of Medicine, Tokyo (T.I.); and Department of Internal Medicine, Iwate Medical University, Morioka (Y.M.), Japan

This paper was presented at the $79^{\text {th }}$ Annual Scientific Meeting of the Japanese Circulation Society, Late Breaking Cohort Studies, April 24-26, 2015, Osaka, Japan.

UMIN ID: 000001128

Mailing address: Mamoru Sakakibara, MD, Department of Cardiovascular Medicine, Hokkaido University Graduate School of Medicine,

Kita 15, Nishi 7, Kita-ku, Sapporo 060-8638, Japan. E-mail: mike.s@ninus.ocn.ne.jp

ISSN-1346-9843 doi:10.1253/circj.CJ-15-1126

All rights are reserved to the Japanese Circulation Society. For permissions, please e-mail: cj@j-circ.or.jp 


\begin{tabular}{|c|c|c|c|c|c|c|c|}
\hline Year & $\begin{array}{l}\text { Study } \\
\text { name }\end{array}$ & Country & $\begin{array}{l}\text { Type of } \\
\text { ACS }\end{array}$ & $\mathbf{n}$ & $\begin{array}{l}\text { Follow-up } \\
\text { period }\end{array}$ & Outcome & Predictors of outcome \\
\hline $2002^{7}$ & JCIS & Japan & $\begin{array}{c}\text { AMI } \\
\text { underwent } \mathrm{PCl}\end{array}$ & 2,221 & 1 year & Mortality & $\begin{array}{l}\text { High age, low LVEF, renal failure, } \\
\text { DM, multivessel disease }\end{array}$ \\
\hline $2004^{8}$ & PRAIS UK & UK & NSTEMI & 653 & $\begin{array}{l}2.4 \text { years } \\
\text { (mean) }\end{array}$ & Mortality & $\begin{array}{l}\text { High age, male sex, low SBP, high } \\
\text { HR, history of HF, ECG change (ST } \\
\text { depression or BBB), history of stroke }\end{array}$ \\
\hline $2005^{9}$ & Single center & Japan & AMI & 415 & $\begin{array}{l}4.0 \text { years } \\
\text { (mean) }\end{array}$ & Mortality & $\begin{array}{l}\text { High age, history of cerebrovascular } \\
\text { disease, renal failure (serum creatinine } \\
\geq 2.0 \mathrm{mg} / \mathrm{dl} \text { ), no } \mathrm{PCl} \text {, Killip class } \geq 2 \text {, } \\
\text { ventricular tachycardia/fibrillation }\end{array}$ \\
\hline $2007^{10}$ & Multicenter & New Zealand & ACS & 1,057 & 4 years & Mortality & $\begin{array}{l}\text { High age, history of IHD, CHF, high HR, } \\
\text { high serum creatinine, high TNI, no } \\
\text { in-hospital PCI, no in-hospital CABG, } \\
\text { history of smoking, no dyslipidemia }\end{array}$ \\
\hline $2011^{11}$ & CRUSADE & USA & $\begin{array}{l}\text { NSTEMI, } \\
\text { Age } \geq 65\end{array}$ & 43,239 & $\begin{array}{l}453 \text { days } \\
\text { (median) }\end{array}$ & Mortality & $\begin{array}{l}\text { High age, male sex, high serum } \\
\text { creatinine, low SBP, HF on } \\
\text { presentation, high HR, low weight, no } \\
\text { hyperlipidemia, low hematocrit, high } \\
\text { troponin, history of stroke, DM, history } \\
\text { of PAD, no family history of CAD, } \\
\text { history of MI, current/recent smoking, no } \\
\text { history of PCI, black/white race, no tran- } \\
\text { sient ST elevation, hypertension }\end{array}$ \\
\hline $2012^{12}$ & Multicenter & USA & AMI & 2,542 & $\begin{array}{c}3-24 \\
\text { months }\end{array}$ & Mortality & $\begin{array}{l}\text { High age, male sex, NSTEMI, low } \\
\text { eGFR, history of HF, history of stroke, } \\
\text { heart failure in hospital, cardiogenic } \\
\text { shock in hospital }\end{array}$ \\
\hline $2013^{13}$ & OACIS & Japan & AMI & 7,870 & $\begin{array}{l}3.9 \text { years } \\
\text { (median) }\end{array}$ & $\begin{array}{c}\text { Recurrent } \\
\mathrm{Ml}\end{array}$ & High age, DM, history of MI \\
\hline
\end{tabular}

ACS, acute coronary syndrome; AMI, acute myocardial infarction; BBB, bundle branch block; CABG, coronary artery bypass grafting; CAD, coronary artery disease; CHF, congestive heart failure; DM, diabetes mellitus; eGFR, estimated glomerular filtration rate; HF, heart failure; HR, heart rate; IHD, ischemic heart disease; LVEF, left ventricular ejection fraction; MI, myocardial infarction; NSTEMI, non-ST-segment elevation $\mathrm{MI}$; PAD, peripheral artery disease; PCl, percutaneous coronary intervention; SBP, systolic blood pressure; TNI, troponin I.

$\mathbf{O}$ ptimal medical therapy (OMT) and the management of coronary risk factors are crucial for the secondary prevention of major adverse cardiac and cerebrovascular events (MACCE) in patients after acute coronary syndrome (ACS).

Risk assessment based on evidence of short-term outcomes in post-ACS patients has been established, ${ }^{1-3}$ and previous studies have reported an improvement in short-term outcomes in post-ACS patients with risk management. ${ }^{4-6}$ However, data on long-term outcomes and predictors are relatively limited.

Previous studies have identified prognostic risk factors for long-term outcomes in post-ACS patients among the clinical variables at the time of hospitalization. ${ }^{7-13}$ Older age, male sex, cardiac shock, multivessel disease, a history of heart failure/ cerebrovascular disease/coronary artery disease (CAD), low left ventricular ejection fraction (LVEF), renal dysfunction, hypertension, or diabetes mellitus (DM) have been reported as major prognostic factors for subsequent adverse outcomes in post-ACS patients (Table 1). In ACS patients, strict management of these factors is needed for secondary prevention. Indeed, OMT and the management of coronary risk factors are recommended in the Japanese Circulation Society (JCS) guidelines for the secondary prevention of MACCE in post-ACS patients. ${ }^{14}$ However, because the effect of patient adherence after discharge on subsequent long-term clinical outcomes has not been investigated in Japanese patients, the present study used the data from the Prevention of AtherothrombotiC Incidents Following Ischemic Coronary Attack (PACIFIC) registry to evaluate long-term adherence to OMT and management of coronary risk factors, and investigate the prognostic risk factors for MACCE after discharge in post-ACS patients,.

\section{Methods}

\section{Patient Population}

The PACIFIC registry was a multicenter, prospective observational study of Japanese ACS patients. A total of 3,597 ACS patients aged $\geq 20$ years were enrolled from 96 hospitals between May 2008 and May 2009 and followed for 2 years. Details of the protocol and results of the main study have been published. ${ }^{15,16}$

In the present study, the analyzed population was patients who received medical therapy for 1 year after discharge from hospital. Therefore, patients who died or had MACCE during hospitalization $(n=119)$ or within 1 year of discharge $(n=110)$, patients lost to follow-up within 1 year after discharge $(n=727)$, and patients with missing data $(\mathrm{n}=54)$ were excluded. Required data included use of antiplatelet agents, angiotensin-converting enzyme inhibitors (ACEI), $\beta$-blockers, and statins, smoking status, body mass index (BMI), blood pressure (BP), low-density lipoprotein-cholesterol (LDL-C), and HbA1c data at 1 year after discharge. Finally, 2,587 patients were included in this study (Figure 1).

\section{Endpoint}

The primary endpoint was defined as the occurrence of MACCE, a composite of fatal myocardial infarction (MI), fatal stroke, other cardiovascular death, non-fatal MI, and non-fatal stroke. . $^{15,16}$ Time to MACCE was calculated from the date at 1 year after discharge to the date of occurrence of MACCE or censoring. 


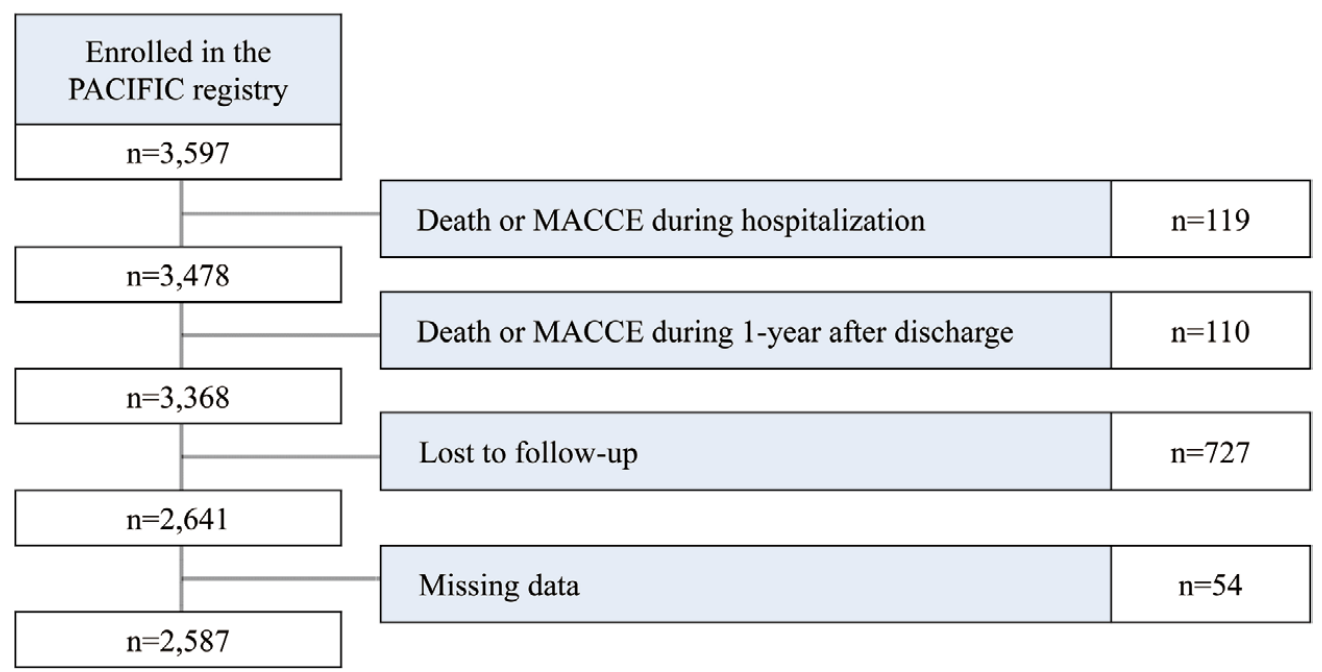

Figure 1. Schematic of the selection of studied patients from the PACIFIC registry. MACCE, major adverse cardiac and cerebrovascular events.

\section{OMT and Candidate Prognostic Risk Factors for MACCE}

A total of 24 variables were considered for the development of a risk model for the occurrence of MACCE (Tables 2,3). According to the JCS guidelines, ${ }^{14} \mathrm{OMT}$ is defined as the use of antiplatelet agents, ACEIs, $\beta$-blockers, and statins. Management goals for coronary risk factors are defined as LDL-cholesterol $<100 \mathrm{mg} / \mathrm{dl}, \mathrm{HbA} 1 \mathrm{c}<7.0 \%$, maintenance of non-smoking status, $\mathrm{BP}<130 / 80 \mathrm{mmHg}$, and $18.5 \leq \mathrm{BMI} \leq 24.9 \mathrm{~kg} / \mathrm{m}^{2}$. The data of OMT adherence and coronary risk factor management at 1 year after discharge were evaluated for each patient and considered as long-term adherence and management. Other variables included age $\geq 75$ years, sex, hypertension, dyslipidemia, DM, type of ACS (MI or unstable angina), LVEF $<35 \%$, estimated glomerular filtration rate (eGFR) $<60 \mathrm{ml} / \mathrm{min}$, fasting glucose $\geq 126 \mathrm{mg} / \mathrm{dl}$, triglycerides $\geq 150 \mathrm{mg} / \mathrm{dl}$, high-density lipoprotein-cholesterol $<40 \mathrm{mg} / \mathrm{dl}$, and a history of MI, atrial fibrillation, cerebral infarction, or peripheral artery disease as candidate prognostic risk factors.

\section{Statistical Analysis}

Baseline characteristics are presented as percentages for categorical variables and median and range for continuous variables.

The incidence of MACCE between 1 and 2 years after discharge was estimated using the Kaplan-Meier method, and a log-rank test was used for statistical comparisons. To identify predictors for the occurrence of MACCE during 1- and 2-year follow-up, Cox regression analysis was performed to determine hazard ratios (HRs) with 95\% confidence intervals (CIs) and $\mathrm{P}$ values. The prognostic value of OMT and management of coronary risk factors at 1 year after discharge were also determined in a multivariate Cox regression analysis. Use of antiplatelet agents was excluded in this model because these were taken by almost all patients during follow-up $(99.6 \%$ at discharge, $98.1 \%$ at 1 year, $97.8 \%$ at 2 years). Variables related to long-term adherence to OMT and management of coronary risk factors were forced into the model. Regarding other candidate factors, variables that were significant in the univariate analysis were also included in the multivariate analysis. Receiver-operating characteristic (ROC) analysis was per-

\begin{tabular}{|lc|}
\hline \multicolumn{2}{|l|}{ Table 2. Baseline Characteristics of the Study Patients } \\
Age (years) & $\mathbf{n = 2 , 5 8 7}$ \\
Male (\%) & $(30-95)$ \\
Concomitant diseases (\%) & 78.4 \\
Diabetes mellitus & \\
Hypertension & 34.4 \\
Dyslipidemia & 73.3 \\
CKD (eGFR <60 ml/min) & 68.5 \\
Dialysis & 30.8 \\
Previous history (\%) & 1.9 \\
Myocardial infarction & \\
Atrial fibrillation & 10.5 \\
Cerebral infarction & 4.0 \\
Peripheral artery disease & 6.7 \\
Type of ACS (\%) & 3.7 \\
Myocardial infarction & \\
Unstable angina & 67.9 \\
LVEF (\%) [UCG/LVG] & 32.1 \\
& $56(10-89)$ \\
\hline
\end{tabular}

Data given as \% or median (range). CKD, chronic kidney disease; LVG, left ventriculography; UCG, ultrasound echocardiography. Other abbreviations as in Table 1.

formed to assess the optimal cut-off level of the identified predictor. All analyses were performed using JMP 11 (SAS Institute Inc, Cary, NC, USA). P-values $<0.05$ were considered statistically significant.

\section{Ethics}

This study was approved by the Ethics Committee of Hokkaido University Hospital, and complied with the Declaration of Helsinki. The protocol of the PACIFIC registry was approved by the ethics committees of each participating institution. All subjects provided written informed consent and all data were anonymized. 
Table 3. Prevalence of Patients Under Optimal Medical Therapy and Management of Coronary Risk Factors

\begin{tabular}{|c|c|c|c|c|}
\hline & \multirow[b]{2}{*}{$\begin{array}{c}\text { Admission } \\
(n=2,587)\end{array}$} & \multirow[b]{2}{*}{$\begin{array}{l}\text { At discharge } \\
(n=2,587)\end{array}$} & \multicolumn{2}{|c|}{ After discharge } \\
\hline & & & $\begin{array}{c}1 \text { year } \\
(n=2,587)\end{array}$ & $\begin{array}{c}2 \text { years } \\
(n=2,544)\end{array}$ \\
\hline \multicolumn{5}{|l|}{ OMT (\%) } \\
\hline Antiplatelet agents & 27.5 & 99.6 & 98.1 & 97.8 \\
\hline ACEls/ARBs & 31.2 & 78.5 & 75.5 & 73.9 \\
\hline ACEls & 6.0 & 31.6 & 24.1 & 23.1 \\
\hline ARBs & 26.5 & 49.6 & 53.8 & 53.3 \\
\hline$\beta$-blockers & 12.2 & 49.4 & 50.2 & 50.2 \\
\hline Statins & 21.1 & 78.6 & 80.4 & 80.6 \\
\hline \multicolumn{5}{|c|}{ Management of risk factors (\%) } \\
\hline LDL-C < $100 \mathrm{mg} / \mathrm{dl}$ & 61.6 & NA & 70.1 & 69.6 \\
\hline $\mathrm{HbA} 1 \mathrm{c}(\mathrm{NGSP})<7.0 \%$ & 77.8 & NA & 82.0 & 80.8 \\
\hline Non-smoking status & 59.2 & NA & 85.1 & 87.4 \\
\hline $\mathrm{BP}<130 / 80 \mathrm{mmHg}$ & 35.4 & NA & 46.0 & 46.3 \\
\hline $18.5 \leq \mathrm{BMI} \leq 24.9 \mathrm{~kg} / \mathrm{m}^{2}$ & 60.3 & NA & 61.1 & 62.4 \\
\hline
\end{tabular}

Data given as \%. ACEl, angiotensin-converting enzyme inhibitor; ARB, angiotensin-receptor blocker; BMl, body mass index; BP, blood pressure; HbA1c, hemoglobin A1c; LDL-C, low-density lipoprotein-cholesterol; NA, not available; NGSP, National glycohemoglobin standardization program; OMT, optimal medical therapy.

Table 4. Predictors of MACCE by Univariate and Multivariate Cox Regression Analyses

\begin{tabular}{|c|c|c|c|c|c|c|}
\hline \multirow{2}{*}{ Variable } & \multicolumn{3}{|c|}{ Univariate analysis } & \multicolumn{3}{|c|}{ Multivariate analysis } \\
\hline & HR & $95 \% \mathrm{Cl}$ & $P$ value & HR & $95 \% \mathrm{Cl}$ & $P$ value \\
\hline \multicolumn{7}{|l|}{ OMT (1 year after discharge) } \\
\hline Antiplatelet agents & 0.26 & $0.10-1.10$ & 0.065 & & & \\
\hline ACEIs & 0.86 & $0.41-1.66$ & 0.670 & 0.83 & $0.13-3.25$ & 0.814 \\
\hline$\beta$-blockers & 1.33 & $0.75-2.41$ & 0.328 & 2.27 & $0.71-8.61$ & 0.171 \\
\hline Statins & 0.57 & $0.31-1.10$ & 0.093 & 0.29 & $0.09-1.06$ & 0.060 \\
\hline \multicolumn{7}{|c|}{$\begin{array}{l}\text { Management of risk factors (1 year after } \\
\text { discharge) }\end{array}$} \\
\hline LDL-C $<100 \mathrm{mg} / \mathrm{dl}$ & 1.07 & $0.51-2.45$ & 0.861 & 1.17 & $0.35-4.68$ & 0.803 \\
\hline $\mathrm{HbA} 1 \mathrm{c}(\mathrm{NGSP})<7.0 \%$ & 0.57 & $0.39-0.87$ & 0.004 & 0.43 & $0.24-0.76$ & 0.004 \\
\hline Non-smoking status & 0.99 & $0.47-2.42$ & 0.979 & 2.14 & $0.40-39.7$ & 0.424 \\
\hline $\mathrm{BP}<130 / 80 \mathrm{mmHg}$ & 0.84 & $0.45-1.54$ & 0.584 & 0.73 & $0.21-2.27$ & 0.587 \\
\hline $18.5 \leq \mathrm{BMI} \leq 24.9 \mathrm{~kg} / \mathrm{m}^{2}$ & 0.94 & $0.50-1.84$ & 0.854 & 2.22 & $0.68-8.72$ & 0.190 \\
\hline \multicolumn{7}{|l|}{ Other risk factors } \\
\hline Female & 2.09 & $1.13-3.74$ & 0.020 & 1.50 & $0.39-4.83$ & 0.522 \\
\hline Age $\geq 75$ years & 2.40 & $1.34-4.27$ & 0.004 & 0.57 & $0.08-2.32$ & 0.464 \\
\hline LVEF $<35 \%$ & 5.50 & $2.20-12.00$ & $<0.001$ & 2.05 & $0.30-8.45$ & 0.413 \\
\hline eGFR $<60 \mathrm{ml} / \mathrm{min}$ & 2.19 & $1.23-3.89$ & 0.008 & 0.79 & $0.20-2.60$ & 0.705 \\
\hline Fasting glucose $\geq 126 \mathrm{mg} / \mathrm{dl}$ & 1.37 & $0.68-2.67$ & 0.368 & & & \\
\hline Triglycerides $\geq 150 \mathrm{mg} / \mathrm{dl}$ & 1.23 & $0.60-2.40$ & 0.564 & & & \\
\hline $\mathrm{HDL}-\mathrm{C}<40 \mathrm{mg} / \mathrm{dl}$ & 1.06 & $0.45-2.24$ & 0.888 & & & \\
\hline $\mathrm{MI}$ & 0.93 & $0.51-1.74$ & 0.789 & & & \\
\hline History of MI & 1.47 & $0.60-3.08$ & 0.370 & & & \\
\hline History of AF & 2.09 & $0.63-5.16$ & 0.203 & & & \\
\hline History of cerebral infarction & 3.45 & $1.57-6.82$ & 0.003 & 3.74 & $0.79-13.2$ & 0.089 \\
\hline History of PAD & 1.39 & $0.23-4.52$ & 0.666 & & & \\
\hline Hypertension & 1.80 & $0.89-4.14$ & 0.109 & & & \\
\hline Dyslipidemia & 0.61 & $0.34-1.11$ & 0.102 & & & \\
\hline Diabetes mellitus & 1.32 & $0.73-2.35$ & 0.354 & & & \\
\hline
\end{tabular}

$\mathrm{AF}$, atrial fibrillation; $\mathrm{Cl}$, confidence interval; HR, hazard ratio; HDL-C, high-density lipoprotein-cholesterol; MACCE, major adverse cardiac and cerebrovascular events; PAD, peripheral artery disease. Other abbreviations as in Tables 1,3. 


\section{Role of the Sponsor and the Authors}

The PACIFIC study was designed by the authors in collaboration with the sponsor (Sanofi, Tokyo, Japan). The sponsor made the PACIFIC database available to the PACIFIC steering committee, and the authors conducted this subanalysis using the data. The draft manuscript was fully reviewed and revised by the authors. The authors and sponsor made the final decision on submission of the article.

\section{Results}

\section{Baseline Characteristics}

The baseline characteristics of the patients $(n=3,597)$ in the overall study have been published previously. ${ }^{16}$ The characteristics of the 2,587 patients included in the present study are shown in Table 2. The incidence of MACCE among these patients between 1 and 2 years after discharge was $1.8 \%$ (47/2,587 patients): 2 patients $(4.3 \%)$ had a fatal MI, 1 (2.1\%) had a fatal stroke, $7(14.9 \%)$ had other cardiovascular deaths, $15(31.9 \%)$ had a non-fatal MI, and $22(46.8 \%)$ had a non-fatal stroke.

\section{Assessment of Adherence to OMT and the Management of Risk Factors}

Almost all patients (97.8-99.6\%) were treated with antiplatelet agents at some time, including at discharge, or 1 or 2 years after discharge (Table 3). The use of statins was as high as 78.6-80.6\% over the 2 years. The use of ACEIs or angiotensin-receptor blockers and $\beta$-blockers at discharge, 1 year and 2 years was approximately $75 \%$ and $50 \%$, respectively, and these rates were stable up to 2 years after discharge.

The percentage of patients with LDL-C $<100 \mathrm{mg} / \mathrm{dl}$ was $70.1 \%$ at 1 year after discharge, and did not change at 2 years (69.6\%). The percentage with $\mathrm{HbA} 1 \mathrm{c}<7.0 \%$ was $82.0 \%$ at 1 year and remained the same at 2 years $(80.8 \%)$. The proportion of patients with $\mathrm{BP}<130 / 80 \mathrm{mmHg}$ was as low as $46.0 \%$ at 1 year and $46.3 \%$ at 2 years. Almost $60 \%$ of patients had $18.5 \leq \mathrm{BMI} \leq 24.9 \mathrm{~kg} / \mathrm{m}^{2}$ at both 1 and 2 years. In contrast, the percentage of patients who did not smoke increased from $59.2 \%$ at the time of admission to $85.1 \%$ at 1 year after discharge and $87.4 \%$ at 2 years.

\section{Independent Predictors Associated With MACCE Between 1 and 2 Years}

In the univariate analysis (Table 4), MACCE was associated with female sex (HR 2.09, 95\% CI 1.13-3.74, $\mathrm{P}=0.020$ ), age $\geq 75$ years (HR 2.40, 95\% CI 1.34-4.27, $\mathrm{P}=0.004$ ), HbA1c $\geq 7.0 \%$ (HR 3.04, 95\% CI 1.32-6.68, P=0.004), LVEF <35\% (HR 5.50, 95\% CI 2.20-12.00, $\mathrm{P}<0.001$ ), eGFR $<60 \mathrm{ml} / \mathrm{min}$ (HR 2.19, 95\% CI 1.23-3.89, $\mathrm{P}=0.008$ ), and a history of cerebral infarction (HR 3.45, 95\% CI 1.57-6.82, $\mathrm{P}=0.003$ ). In the multivariate analysis incorporating the risk factors that were significant in the univariate analysis, $\mathrm{HbA} 1 \mathrm{c}<7.0 \%$ at 1 -year follow-up was significantly associated with a lower risk of MACCE between 1 and 2 years after discharge (HR $0.43,95 \%$ CI $0.24-0.76, \mathrm{P}=0.004)$. According to the ROC analysis, the optimal cut-off level of HbA1c was determined to be $6.4 \%$ (area under curve 0.65) (Figure 2).

We further conducted subgroup analysis stratified by the presence of DM. HbA1c $\geq 6.4 \%$ was found to be an independent predictor of MACCE $(\mathrm{P}=0.012)$ in the subgroup of DM patients, but not in patients without DM (Table 5). LVEF $<35 \%(\mathrm{P}=0.004)$ and a history of cerebral infarction $(\mathrm{P}=0.002)$ were associated with MACCE in patients without DM.

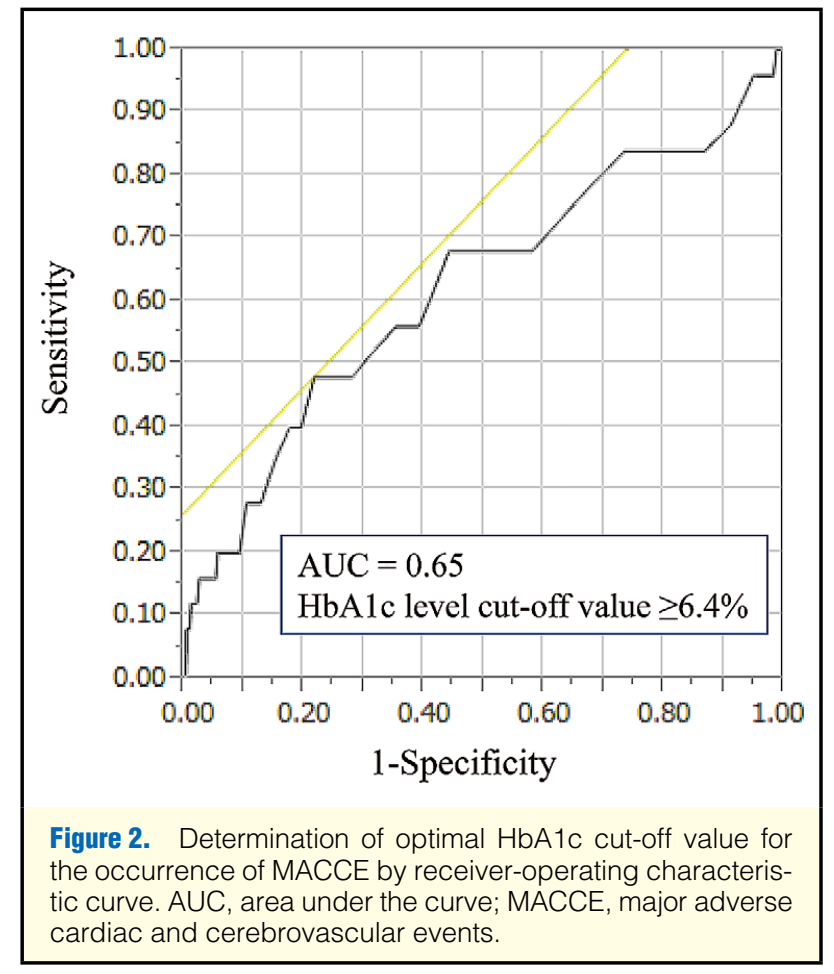

\section{Discussion}

This is the first report to evaluate the long-term prognosis of adherence to OMT and medical management of coronary risk factors after discharge, based on JCS guidelines, in Japanese post-ACS patients. The unique feature of this study was that it assessed long-term adherence to OMT as well as management of coronary risk factors as predictors of long-term MACCE. The PACIFIC registry contained all the data that enabled us to identify the risk factors for MACCE during long-term follow-up.

The most important finding of the present study was that a lower HbA1c level was independently associated with a lower risk of MACCE in post-ACS patients, and that the optimal cut-off level of HbA1c for secondary prevention of MACCE was $6.4 \%$. These results are consistent with previous studies showing a correlation between intensive glycemic control and favorable cardiovascular outcomes. ${ }^{17-19}$ Similar findings were also reported by the PROactive study, in which pioglitazone treatment was associated with a significantly lower rate of fatal and non-fatal MI and ACS in DM patients with greater decline in median HbA1c. ${ }^{20}$ These findings also support recommendations for the optimal $\mathrm{HbA} 1 \mathrm{c}$ level for secondary prevention to be $<7.0 \%$ in the Japanese guidelines, ${ }^{14}$ and also in the American Heart Association and American College of Cardiology Foundation guidelines. ${ }^{21}$ The European Society of Cardiology guidelines recommend a target $\mathrm{HbA} 1 \mathrm{c}$ level $<7.0 \%$ for primary prevention of cardiovascular disease (class I, level of evidence A). ${ }^{22}$

In contrast, several recent studies have reported that intensive glycemic control may increase adverse events. ${ }^{23,24}$ Currie et al reported that type $2 \mathrm{DM}$ patients with lower levels of controlled HbA1c had increased all-cause deaths and cardiac events compared with DM patients with median HbA1c $7.5 \% .{ }^{23}$ In the ACCORD study, intensive glycemic control (goal $\mathrm{HbA} 1 \mathrm{c}<6.0 \%$ and median $\mathrm{HbA} 1 \mathrm{c}$ at 1 year $6.4 \%$ ) was associated with higher mortality rates compared with standard 


\begin{tabular}{|c|c|c|c|c|c|c|c|c|}
\hline \multirow{3}{*}{ Variable } & \multicolumn{4}{|c|}{ Diabetes mellitus $(n=890)$} & \multicolumn{4}{|c|}{ No diabetes mellitus $(n=1,697)$} \\
\hline & \multirow{2}{*}{$\begin{array}{c}\text { Univariate } \\
\text { P-value }\end{array}$} & \multicolumn{3}{|c|}{ Multivariate } & \multirow{2}{*}{$\begin{array}{l}\text { Univariate } \\
\text { P-value }\end{array}$} & \multicolumn{3}{|c|}{ Multivariate } \\
\hline & & HR & $95 \% \mathrm{Cl}$ & P-value & & HR & $95 \% \mathrm{Cl}$ & P-value \\
\hline \multicolumn{9}{|l|}{ OMT (1 year after discharge) } \\
\hline Antiplatelet agents & 0.577 & - & - & - & 0.001 & & & \\
\hline ACEls & 0.622 & - & - & - & 0.397 & - & - & - \\
\hline$\beta$-blockers & 0.073 & - & - & - & 0.863 & - & - & - \\
\hline Statins & 0.961 & - & - & - & 0.019 & 0.55 & $0.21-1.52$ & 0.234 \\
\hline \multicolumn{9}{|c|}{$\begin{array}{l}\text { Management of risk factor ( } 1 \text { year } \\
\text { after discharge) }\end{array}$} \\
\hline LDL-C $<100 \mathrm{mg} / \mathrm{dl}$ & 0.562 & - & - & - & 0.785 & - & - & - \\
\hline $\mathrm{HbA} 1 \mathrm{c}(\mathrm{NGSP})<7.0 \%$ & 0.053 & - & - & - & 0.219 & - & - & - \\
\hline $\mathrm{HbA} 1 \mathrm{c}(\mathrm{NGSP})<6.4 \%$ & 0.016 & 0.19 & $0.03-0.72$ & 0.012 & 0.417 & - & - & - \\
\hline Non-smoking status & 0.548 & - & - & - & 0.591 & - & - & - \\
\hline $\mathrm{BP}<130 / 80 \mathrm{mmHg}$ & 0.287 & - & - & - & 0.765 & - & - & - \\
\hline $18.5 \leq \mathrm{BMI} \leq 24.9 \mathrm{~kg} / \mathrm{m}^{2}$ & 0.673 & - & - & - & 0.886 & - & - & - \\
\hline \multicolumn{9}{|l|}{ Other risk factors } \\
\hline Female & 0.012 & 1.71 & $0.51-5.30$ & 0.366 & 0.293 & - & - & - \\
\hline Age $\geq 75$ years & 0.004 & 0.51 & $0.40-4.79$ & 0.515 & 0.098 & - & - & - \\
\hline LVEF $<35 \%$ & 0.080 & - & - & - & $<0.001$ & 5.89 & $1.91-15.2$ & 0.004 \\
\hline eGFR $<60 \mathrm{ml} / \mathrm{min}$ & 0.081 & - & - & - & 0.039 & 0.91 & $0.34-2.24$ & 0.843 \\
\hline Fasting glucose $\geq 126 \mathrm{mg} / \mathrm{dl}$ & 0.893 & & & & 0.173 & & & \\
\hline Triglycerides $\geq 150 \mathrm{mg} / \mathrm{dl}$ & 0.992 & & & & 0.460 & & & \\
\hline $\mathrm{HDL}-\mathrm{C}<40 \mathrm{mg} / \mathrm{dl}$ & 0.687 & & & & 0.623 & & & \\
\hline $\mathrm{Ml}$ & 0.432 & - & - & - & 0.342 & - & - & - \\
\hline History of MI & 0.672 & - & - & - & 0.399 & - & - & - \\
\hline History of AF & 0.759 & - & - & - & 0.107 & - & - & - \\
\hline History of cerebral infarction & 0.230 & - & - & - & $<0.001$ & 6.04 & $2.10-15.3$ & 0.002 \\
\hline History of PAD & 0.329 & - & - & - & 0.068 & - & - & - \\
\hline Hypertension & 0.835 & - & - & - & 0.056 & - & - & - \\
\hline Dyslipidemia & 0.741 & - & - & - & 0.044 & - & - & - \\
\hline Insulin & 0.127 & - & - & - & - & - & - & - \\
\hline Sulfonylureas & 0.264 & - & - & - & - & - & - & - \\
\hline Thiazolidinediones & 0.425 & - & - & - & - & - & - & - \\
\hline
\end{tabular}

HR, hazard ratio. Other abbreviations as in Tables 1,3,4.

glycemic control (goal HbA1c 7.0-7.9\% and median HbA1c at 1 year $7.5 \%$ ) in type $2 \mathrm{DM}$ patients with either known CAD or cardiovascular risk factors. ${ }^{24}$ However, it was also found that intensive glycemic control decreased the incidence of MI, coronary revascularization, and unstable angina in these patients. ${ }^{19}$ The reason for these discrepant findings is not clear. A subanalysis of the ACCORD study reported that high average $\mathrm{HbA} 1 \mathrm{c}$ was strongly associated with death, and in particular, patients with $\mathrm{HbA1c}>7.0 \%$ despite intensive glucose control therapy had a high mortality risk. ${ }^{25}$ These results are in accord with our findings. Previous studies also reported that hypoglycemia was associated with an increase in the risk of death ${ }^{26}$ or CAD. ${ }^{27}$ However, the incidence of hypoglycemic events was not available in the present study. Further studies are needed to determine the optimal long-term goal for glycemic control as secondary prevention in ACS patients.

The present study included both DM and non-DM patients. In the subgroup of patients with $\mathrm{DM}, \mathrm{HbA} 1 \mathrm{c} \geq 6.4 \%$ was also an independent predictor of MACCE but not in the subgroup of patients without DM. In non-DM patients, $\mathrm{LVEF}<35 \%$ and a history of cerebral infarction were associated with MACCE. Therefore, glycemic control is considered to be especially important in post-ACS patients with DM. There was no significant relationship between insulin use and MACCE.

In the univariate analysis, MACCE was associated with female sex, age $\geq 75$ years, $\mathrm{HbA} 1 \mathrm{c} \geq 7.0 \%$, LVEF $<35 \%$, eGFR $<60 \mathrm{ml} / \mathrm{min}$, and a history of cerebral infarction. These results are consistent with previous studies except for the association with sex. ${ }^{7-13}$ In the present study, non-fatal stroke accounted for $46.8 \%$ (22/47) of MACCE events, and female patients had a significantly higher incidence of non-fatal stroke than male patients. A previous study also demonstrated that female sex was a predictor of stroke after MI. ${ }^{28}$ The reason why female sex was a predicator for MACCE in the present study might be related to the higher incidence of non-fatal stroke after MI in females.

The long-term administration of antiplatelet agents and statins was high, at approximately $100 \%$ and $80 \%$, respectively, in agreement with previous studies. ${ }^{29,30}$ In contrast, ACEIs and $\beta$-blockers were used in only $25 \%$ and $50 \%$ of patients, respectively. ACEIs have been shown to reduce edeaths and MACCE in patients with $\mathrm{MI}^{31,32}$ and are recommended for all CAD patients according to the guidelines. ${ }^{14,21}$ The clinical benefit of ACEI therapy is especially important in patients 
with LV dysfunction. ${ }^{33}$ However, ACEI efficacy is also reported in patients with preserved LVEF. ${ }^{34}$ The favorable effects of $\beta$-blockers are also well established in ACS patients. ${ }^{35}$ However, in the present study, $\beta$-blockers were used only in half of the post-ACS patients at discharge and thereafter. A higher incidence of coronary artery spasm might be responsible for the lower use of $\beta$-blockers. However, according to the guidelines, it is necessary that ACEIs and $\beta$-blockers are used more in eligible patients even though their use was not an independent predictor for MACCE in the present analysis.

\section{Study Limitations}

There are several potential limitations that should be acknowledged in the present study. First, important clinical variables such as history of heart failure, LVEF at 1-year follow-up, hypoglycemic events, duration of DM, and adverse effects of drugs were not included in the present study. Therefore, we could not study their effect on the outcomes in post-ACS patients in the present study. Second, favorable effects of physical activity and exercise have been well established for secondary prevention in CAD patients. ${ }^{36}$ However, these factors were not assessed in the present study. Third, the duration of follow-up was 2 years after the onset of ACS. Longer term investigations are definitely needed to generalize the present findings to post-ACS patients. Finally, the number of events was too small to detect the intermediate (eg, $\approx 0.7$ of true HR) predictors in the study. Further clarification in a larger study is needed if the prognostic values of intermediate predictors are to be evaluated. However, the beneficial effect of glycemic control is clear even during follow-up of 1 year. Therefore, the effect of hyperglycemia on MACCE should be more significant in the long-term.

In conclusion, maintenance of lower HbA1c after discharge was strongly associated with a lower risk of subsequent MACCE in Japanese post-ACS patients. Of several potential risk factors, hyperglycemia was found to be a crucial treatment target for the long-term secondary prevention of MACCE in post-ACS patients.

\section{Acknowledgments}

The authors thank all the enrolled patients, participating cardiologists and other medical professionals who contributed substantially to this cooperative study. The PACIFIC investigators other than authors are listed in the appendix of a previous paper. ${ }^{16}$

\section{Disclosures}

K.M. has received speakers' bureau/honoraria from MSD, AstraZeneca, Kowa Pharmaceutical, Sanofi, Shionogi, Daiichi-Sankyo, Takeda Pharmaceutical, Pfizer, Astellas Pharma, and Novartis Pharma.

H. Ogawa has received speakers' bureau/honoraria from Actelion Pharmaceuticals Japan, AstraZeneca, Bayer Yakuhin, Nippon Boehringer Ingelheim, Daiichi-Sankyo, Eisai, Kowa Pharmaceutical, Kyowa Hakko Kirin, Mitsubishi Tanabe Pharma, MSD, Otsuka Pharmaceutical, Pfizer, Sanofi, Takeda Pharmaceutical, and Teijin Pharma, and grants from Astellas Pharma, Bayer Yakuhin, Bristol-Myers Squibb, Chugai Pharmaceutical, Daiichi-Sankyo, Dainippon Sumitomo Pharma, Mochida Pharmaceutical, MSD, Novartis Pharma, Otsuka Pharmaceutical, Ono Pharmaceutical, Pfizer, Sanofi, Shionogi, and Takeda Pharmaceutical.

H.Y. has received remuneration for lectures from Daiichi-Sankyo, Sanofi, Takeda Pharmaceutical, MSD, AstraZeneca, Mochida Pharmaceutical, Sanofi, Terumo, Boston Scientific Japan, Abbott Vascular Japan, and Medtronic Japan, and scholarship funds from Takeda Pharmaceutical and Daiichi-Sankyo.

M.M. has received speakers' bureau/honoraria from Otsuka Pharmaceutical, Sanofi, Nippon Boehringer Ingelheim, Daiichi-Sankyo, and Bayer Yakuhin.

M.K. reports no conflict of interest for this work, with personal fees from Takeda Pharmaceutical and Ono Pharmaceutical, and research grants from Mitsubishi Tanabe Pharma and Novartis Pharma outside the submitted work.

T.K. has received an honorarium and research grants from Sanofi.

Y.I. has received speakers' bureau/honoraria from MSD, AstraZeneca, Sanofi, Daiichi-Sankyo, Takeda Pharmaceutical, Pfizer, Astellas Pharma, and Bayer Yakuhin, research grants from Sanofi, Daiichi-Sankyo, Pfizer, Bayer Yakuhin, and MSD, advisory fees from Terumo, Kaneka, and Nipro, and a royalty from Terumo.

K. Kimura has received speakers' bureau/honoraria from MSD, Bayer Yakuhin, and Daiichi-Sankyo, and research funds from Toa Eiyo, Bayer Yakuhin, MSD, Astellas Pharma, AstraZeneca, Sanofi, Eli Lilly Japan, Research Institute for Production Development, Pfizer, Shionogi, Kowa Pharmaceutical, Daiichi-Sankyo, Mitsubishi Tanabe Pharma, Ono Pharmaceutical, Nippon Boehringer Ingelheim, Takeda Pharmaceutical, and Otsuka Pharmaceutical.

T.I. has received speakers' bureau/honoraria from Sanofi, DaiichiSankyo, AstraZeneca, Shionogi, Takeda Pharmaceutical, MSD, Astellas Pharma, Mochida Pharmaceutical, and Otsuka Pharmaceutical, and research funds from Takeda Pharmaceutical, Daiichi-Sankyo, Nippon Boehringer Ingelheim, Sanofi, Pfizer, and Mitsubishi Tanabe Pharma.

Y.M. has received speakers' bureau/honoraria and research grants from Sanofi, Daiichi-Sankyo, and Bayer Yakuhin.

H.D. has received speakers' bureau/honoraria from MSD, AstraZeneca, Kowa Pharmaceutical, Sanofi, GlaxoSmithKline, Shionogi, Daiichi-Sankyo, Takeda Pharmaceutical, Mitsubishi Tanabe Pharma, Pfizer, and Astellas Pharma, and research funds from Takeda Pharmaceutical, Bristol-Myers Squibb, Nippon Boehringer Ingelheim, Astellas Pharma, Novartis Pharma, MSD, Sanofi, Otsuka Pharmaceutical, Dainippon Sumitomo Pharma, Pfizer, Kowa Pharmaceutical, Shionogi, AstraZeneca, Teijin, and Morinaga Milk Industry.

H.T. has received speakers' bureau/honoraria from MSD, Ono Pharmaceutical, Takeda Pharmaceutical, Mitsubishi Tanabe Pharma, DaiichiSankyo, Teijin, Nippon Boehringer Ingelheim, Bayer Yakuhin, Pfizer, and Bristol-Myers Squibb, research funds from Takeda Pharmaceutical, Nippon Boehringer Ingelheim, Mitsubishi Tanabe Pharma, and Daiichi-Sankyo, and consultation fees from Novartis Pharma, Ono Pharmaceutical, and Pfizer.

The other authors declare no conflicts of interest related to this article.

\section{Grant}

This study was supported by Sanofi, Tokyo Japan.

\section{References}

1. Granger CB, Goldberg RJ, Dabbous O, Pieper KS, Eagle KA, Cannon $\mathrm{CP}$, et al. Predictors of hospital mortality in the global registry of acute coronary events. Arch Intern Med 2003; 163: 2345-2353.

2. Antman EM, Cohen M, Bernink PJ, McCabe CH, Horacek T, Papuchis $\mathrm{G}$, et al. The TIMI risk score for unstable angina/non-ST elevation MI: A method for prognostication and therapeutic decision making. JAMA 2000; 284: 835-842.

3. Fujii T, Suzuki T, Torii S, Murakami T, Nakano M, Nakazawa G, et al. Diagnostic accuracy of Global Registry of Acute Coronary Events (GRACE) risk score in ST-elevation myocardial infarction for inhospital and 360-day mortality in Japanese patients. Circ J 2014; 78: $2950-2954$

4. Krumholz HM, Wang Y, Chen J, Drye EE, Spertus JA, Ross JS, et al. Reduction in acute myocardial infarction mortality in the United States: Risk-standardized mortality rates from 1995-2006. JAMA 2009; 302: 767-773.

5. Takii T, Yasuda S, Takahashi J, Ito K, Shiba N, Shirato K, et al. Trends in acute myocardial infarction incidence and mortality over 30 years in Japan. Circ J 2010; 74: 93-100.

6. Ishihara M, Fujino M, Ogawa H, Yasuda S, Noguchi T, Nakao K, et al. Clinical presentation, management and outcome of Japanese patients with acute myocardial infarction in the troponin era: Japanese registry of acute myocardial infarction diagnosed by universal definition (J-MINUET). Circ J 2015; 79: 1255-1262.

7. Shihara M, Tsutsui H, Tsuchihashi M, Tada H, Kono S, Takeshita A. In-hospital and one-year outcomes for patients undergoing percutaneous coronary intervention for acute myocardial infarction. Am J Cardiol 2002; 90: 932-936.

8. Taneja AK, Collinson J, Flather MD, Bakhai A, de Arenaza DP, Wang D, et al. Mortality following non-ST elevation acute coronary syndrome: 4 years follow-up of the PRAIS UK Registry (Prospective Registry of Acute Ischaemic Syndromes in the UK). Eur Heart $J$ 2004; 25: 2013-2018.

9. Kinoshita N, Imai K, Kinjo K, Naka M. Longitudinal study of acute myocardial infarction in the southeast Osaka district from 1988 to 2002. Circ J 2005; 69: 1170-1175. 
10. Tang EW, Wong CK, Herbison P. Global Registry of Acute Coronary Events (GRACE) hospital discharge risk score accurately predicts long-term mortality post acute coronary syndrome. Am Heart J 2007; 153: $29-35$.

11. Roe MT, Chen AY, Thomas L, Wang TY, Alexander KP, Hammill $\mathrm{BG}$, et al. Predicting long-term mortality in older patients after nonST-segment elevation myocardial infarction: The CRUSADE longterm mortality model and risk score. Am Heart J 2011; 162: 875-883.e1, doi:10.1016/j.ahj.2011.08.010.

12. Coles AH, Fisher KA, Darling C, McManus D, Maitas O, Yarzebski $\mathrm{J}$, et al. Recent trends in post-discharge mortality among patients with an initial acute myocardial infarction. Am J Cardiol 2012; 110: $1073-1077$.

13. Nakatani D, Sakata Y, Suna S, Usami M, Matsumoto S, Shimizu M, et al. Incidence, predictors, and subsequent mortality risk of recurrent myocardial infarction in patients following discharge for acute myocardial infarction. Circ J 2013; 77: 439-446.

14. JCS Joint Working Group. Guidelines for secondary prevention of myocardial infarction (JCS 2011): Digest version. Circ J 2013; 77: $231-248$.

15. Miyauchi K, Morino Y, Tsukahara K, Origasa H, Daida H; PACIFIC steering committee members. The PACIFIC (Prevention of AtherothrombotiC Incidents Following Ischemic Coronary attack) Registry: Rationale and design of a 2-year study in patients initially hospitalised with acute coronary syndrome in Japan. Cardiovasc Drugs Ther 2010; 24: 77-83.

16. Daida H, Miyauchi K, Ogawa H, Yokoi H, Matsumoto M, Kitakaze $\mathrm{M}$, et al. Management and 2-year long-term clinical outcome of acute coronary syndrome in Japan. Circ J 2013; 77: 934-943.

17. Holman RR, Paul SK, Bethel MA, Matthews DR, Neil HA. 10-year follow-up of intensive glucose control in type 2 diabetes. $N$ Engl $J$ Med 2008; 359: 1577-1589.

18. Ray KK, Seshasai SR, Wijesuriya S, Sivakumaran R, Nethercott S, Preiss D, et al. Effect of intensive control of glucose on cardiovascular outcomes and death in patients with diabetes mellitus: A meta-analysis of randomised controlled trials. Lancet 2009; 373: 1765-1772.

19. Gerstein HC, Miller ME, Ismail-Beigi F, Largay J, McDonald C, Lochnan HA, et al. Effects of intensive glycaemic control on ischaemic heart disease: Analysis of data from the randomised, controlled ACCORD trial. Lancet 2014; 384: 1936-1941.

20. Erdmann E, Dormandy JA, Charbonnel B, Massi-Benedetti M, Moules IK, Skene AM. The effect of pioglitazone on recurrent myocardial infarction in 2,445 patients with type 2 diabetes and previous myocardial infarction: Results from the PROactive (PROactive 05) study. J Am Coll Cardiol 2007; 49: 1772-1780.

21. Smith SC Jr, Benjamin EJ, Bonow RO, Braun LT, Creager MA, Franklin BA, et al. AHA/ACCF Secondary Prevention and Risk Reduction Therapy for Patients with Coronary and other Atherosclerotic Vascular Disease: 2011 update: A guideline from the American Heart Association and American College of Cardiology Foundation. Circulation 2011; 124: 2458-2473.

22. Perk J, De Backer G, Gohlke H, Graham I, Reiner Z, Verschuren M, et al. European Guidelines on cardiovascular disease prevention in clinical practice (version 2012): The Fifth Joint Task Force of the European Society of Cardiology and Other Societies on Cardiovascular Disease Prevention in Clinical Practice (constituted by representatives of nine societies and by invited experts). Eur Heart $J$
2012; 33: $1635-1701$

23. Currie CJ, Peters JR, Tynan A, Evans M, Heine RJ, Bracco OL, et al. Survival as a function of $\mathrm{HbA}(1 \mathrm{c})$ in people with type 2 diabetes: A retrospective cohort study. Lancet 2010; 375: 481-489.

24. Gerstein HC, Miller ME, Byington RP, Goff DC Jr, Bigger JT, Buse $\mathrm{JB}$, et al. Effects of intensive glucose lowering in type 2 diabetes. $N$ Engl J Med 2008; 358: 2545-2559.

25. Riddle MC, Ambrosius WT, Brillon DJ, Buse JB, Byington RP, Cohen RM, et al. Epidemiologic relationships between A1C and all-cause mortality during a median 3.4-year follow-up of glycemic treatment in the ACCORD trial. Diabetes Care 2010; 33: 983-990.

26. Bonds DE, Miller ME, Bergenstal RM, Buse JB, Byington RP, Cutler JA, et al. The association between symptomatic, severe hypoglycaemia and mortality in type 2 diabetes: Retrospective epidemiological analysis of the ACCORD study. BMJ 2010; 340: b4909.

27. Goto A, Arah OA, Goto M, Terauchi Y, Noda M. Severe hypoglycaemia and cardiovascular disease: Systematic review and metaanalysis with bias analysis. BMJ 2013; 347: $\mathrm{f} 4533$.

28. Spencer FA, Gore JM, Yarzebski J, Lessard D, Jackson EA, Goldberg RJ. Trends (1986 to 1999) in the incidence and outcomes of in-hospital stroke complicating acute myocardial infarction (The Worcester Heart Attack Study). Am J Cardiol 2003; 92: 383-388.

29. Bi Y, Gao R, Patel A, Su S, Gao W, Hu D, et al. Evidence-based medication use among Chinese patients with acute coronary syndromes at the time of hospital discharge and 1 year after hospitalization: Results from the Clinical Pathways for Acute Coronary Syndromes in China (CPACS) study. Am Heart $J$ 2009; 157: 509-516.e1, doi:10.1016/j.ahj.2008.09.026.

30. Wang R, Neuenschwander FC, Lima Filho A, Moreira CM, Santos $\mathrm{ES}$, Reis HJ, et al. Use of evidence-based interventions in acute coronary syndrome: Subanalysis of the ACCEPT registry. Arq Bras Cardiol 2014; 102: 319-326.

31. Pedrazzini G, Santoro E, Latini R, Fromm L, Franzosi MG, Mocetti $\mathrm{T}$, et al. Causes of death in patients with acute myocardial infarction treated with angiotensin-converting enzyme inhibitors: Findings from the Gruppo Italiano per lo Studio della Sopravvivenza nell'Infarto (GISSI)-3 trial. Am Heart J 2008; 155: 388-394.

32. ISIS-4 (Fourth International Study of Infarct Survival) Collaborative Group. ISIS-4: A randomised factorial trial assessing early oral captopril, oral mononitrate, and intravenous magnesium sulphate in 58,050 patients with suspected acute myocardial infarction. Lancet 1995; 345: 669-685.

33. Pfeffer MA, Braunwald E, Moye LA, Basta L, Brown EJ Jr, Cuddy TE, et al. Effect of captopril on mortality and morbidity in patients with left ventricular dysfunction after myocardial infarction: Results of the survival and ventricular enlargement trial: The SAVE Investigators. N Engl J Med 1992; 327: 669-677.

34. Fox KM. Efficacy of perindopril in reduction of cardiovascular events among patients with stable coronary artery disease: Randomised, double-blind, placebo-controlled, multicentre trial (the EUROPA study). Lancet 2003; 362: 782-788.

35. The Beta-Blocker Pooling Project Research Group. The BetaBlocker Pooling Project (BBPP): Subgroup findings from randomized trials in post infarction patients. Eur Heart J 1988; 9: 8-16.

36. Oldridge NB, Guyatt GH, Fischer ME, Rimm AA. Cardiac rehabilitation after myocardial infarction: Combined experience of randomized clinical trials. JAMA 1988; 260: 945-950. 